\title{
ESTRUTURA URBANA E ATIVIDADE TECNOLÓGICA EM MINAS GERAIS*
}

\author{
Eduardo Gonçalves ${ }^{\S}$
}

\section{RESUMO}

Este trabalho utiliza uma base de dados de patentes do Instituto Nacional de Propriedade Industrial (INPI), com o objetivo de preencher algumas lacunas na literatura sobre o tema que relaciona inovação e desenvolvimento regional em Minas Gerais. Estes objetivos são os seguintes: 1) identificar os principais fatores determinantes da inovação nos municípios mineiros a partir dos fatores considerados relevantes pela literatura internacional; 2) determinar a relação que existe entre a estrutura urbana do Estado e a inovação; 3) revelar padrões de associação espaciais e identificar agrupamentos espaciais significativos de produção tecnológica; 4) verificar se ocorrem transbordamentos tecnológicos intermunicipais. O trabalho constatou que a atividade tecnológica é concentrada espacialmente, e tende a ocorrer principalmente ao redor da área metropolitana de Belo Horizonte. A estrutura urbana do Estado é, em parte, causadora desta distribuição espacial da atividade tecnológica, porque a maior parte das cidades não possui escala urbana e requisitos exigidos pela inovação.

Palavras-chave: atividade tecnológica, patentes, estrutura urbana, Minas Gerais.

\section{ABSTRACT}

This paper uses a database of patent applications from the Brazilian Patent Office (INPI) to throw some light on the relationship between innovation and regional development in the state of Minas Gerais. The objectives are described as follows: 1) to identify the main determinants of innovation in the municipalities of Minas Gerais considering the variables emphasized by the international literature; 2) to determine the relation existing between the urban structure of the state of Minas Gerais and its innovative performance; 3) to reveal the patterns of spatial associations and to identify significant spatial clustering of technological activity; 4) to verify the occurrence of interregional knowledge spillovers. The results showed that the innovative activity is spatially concentrated and presents a major tendency to take place around the metropolitan area of Belo Horizonte. The urban structure of the state is pointed out as a cause of this spatial distribution of the technological activity because great part of its municipalities do not have urban scale and minimum conditions required by the innovative process.

Key words: technological activity, patents, urban structure, Minas Gerais.

JEL classification: R12, O30, C21.

\footnotetext{
* O autor agradece ao Prof. Eduardo da Motta e Albuquerque pela cessão dos dados de patentes, os quais tiveram a contribuição dos pesquisadores Adriano Ricardo Baessa e Leandro Alves Silva. Créditos são também estendidos às valiosas sugestões do Prof. Eduardo Simões de Almeida e aos dois pareceristas anônimos desta revista. Os erros ou omissões deste trabalho são, porém, de responsabilidade exclusiva do autor.

$\S$ Professor da Faculdade de Economia e Administração - FEA - Universidade Federal de Juiz de Fora - UFJF. Endereço para contato: Campus Universitário - Cidade Universitária - Faculdade de Economia e Administração - UFJF - Juiz de Fora - MG - (32) 32293532. E-mail: eduardo.goncalves@ufjf.edu.br.

Recebido em fevereiro de 2006. Aprovado em julho de 2006.
} 


\section{INTRODUÇÃO}

A literatura internacional apresenta argumentos variados para explicar o caráter urbano da inovação. Segundo Simmie (2001), a introdução de novos produtos no mercado é altamente dependente de externalidades. O conceito de economias de aglomeração compreende diversos tipos de externalidades, que são importantes tanto para explicar a aglomeração espacial da produção quanto da inovação, tendo em vista que as concentrações espaciais de produção e inovação são fortemente correlacionadas. (Audretsch e Feldman, 1996).

Para explicar a inovação, alguns autores destacam as economias de localização, realçando a especialização setorial da indústria de uma região. Quanto maior fosse a concentração industrial naquele setor específico, mais facilmente ocorreriam transbordamentos de conhecimento tecnológico de uma firma para outra, fomentando a inovação regional. $\mathrm{O}$ desenvolvimento pioneiro deste raciocínio se deve a Marshall (1982), mas também recebeu contribuições de Arrow (1962) e Romer (1986). Por isso, Glaeser et al. (1992) denominam tal externalidade de Marshall-Arrow-Romer.

Outros autores dão mais ênfase à diversidade do ambiente regional e urbano, representada pelo conceito de economias de urbanização. O reconhecimento da importância da dimensão urbana para inovar remonta ao trabalho de Jacobs (1969). A tese de que a diversidade promove inovação é confirmada por trabalhos empíricos, como o de Feldman e Audretsch (1999). Além de afirmarem que a especialização diminuía a inovação nas cidades, o trabalho sugeriu que a inovação tendia a ocorrer mais à medida que o tamanho urbano crescia.

Simmie (2001) afirma que as áreas urbanas, ao concentrarem economias de aglomeração, permitiriam atingir maior eficiência estática e reduzir incerteza e risco do processo inovador. A escala urbana também seria importante por outras duas razões. Primeiro, porque grandes cidades são capazes de atrair inventores e de dar condições de desenvolvimento às suas idéias. (Wood, 2001). Segundo, porque quanto maior o tamanho urbano, maiores são as chances de interações locais lucrativas, devido à lei dos grandes números e ao mecanismo de seleção natural dos negócios que se beneficiam das múltiplas oportunidades oferecidas. (Simmie, 2001).

Outras evidências são discutidas por Wood (2001), que destaca tipos particulares de ativos urbanos, que se baseiam em conhecimentos específicos que transbordam de outras características da dimensão urbana e que favorecem as grandes cidades. Daí a força inovadora das metrópoles. Grandes cidades ofereceriam vantagens relacionadas a múltiplos agrupamentos de atividades, envolvendo vários tipos de mercados, tecnologias e empresas. As cidades menores, por outro lado, seriam mais dependentes de um ou alguns setores-chave ou de investimentos de uma grande empresa. Desta forma, "diferentes escalas urbanas suportam diferentes tipos de inovação".

Os ativos urbanos podem ser vistos também como requisitos para compartilhar transbordamentos de conhecimento tecnológico que fluem do espaço geográfico imediato. (Jaffe et al., 1993; Varga, 1998; Fischer e Varga, 2003). Esta constatação explica a necessidade de as firmas estarem próximas entre si para aproveitar esses transbordamentos.

Avaliar os determinantes da inovação em Minas Gerais é o objetivo deste artigo, especialmente quando se leva em consideração a sua marcante heterogeneidade social e econômica. Diversos autores já destacaram a concentração da produção e da atividade inovadora no Estado. (Silva, 1997; Albuquerque, 2001).

Ainda que tenham grande relevância ao fazer um mapeamento inicial da atividade tecnológica, sobretudo por meio de indicadores de patentes, os trabalhos existentes sobre inovação em Minas Gerais não esgotaram o tema. Além disso, é preciso fazer uso de técnicas econométricas espaciais 
para tentar preencher algumas lacunas na literatura empírica que relaciona inovação e desenvolvimento regional e urbano no Estado, como: 1) identificar os principais fatores determinantes da inovação nos municípios mineiros a partir dos fatores considerados relevantes pela literatura internacional e nacional; 2) determinar a relação que existe entre a estrutura urbana do Estado e a inovação; 3) revelar padrões de associação espaciais e identificar agrupamentos espaciais significativos de produção tecnológica; 4) verificar se ocorrem transbordamentos tecnológicos intermunicipais.

Para atingir estes objetivos, o artigo está dividido em mais três seções. Na próxima, detalhes dos procedimentos metodológicos são apresentados, como a forma pela qual as variáveis foram construídas, as fontes de dados usadas para sua construção e as técnicas exploratórias (Análise Exploratória de Dados Espaciais e Análise Fatorial) e econométricas utilizadas. Na terceira seção, os resultados da aplicação destas técnicas são expostos, sendo que na última seção são apresentadas as principais conclusões e recomendações de políticas públicas.

\section{Procedimentos metodológicos}

\subsection{Definição de variáveis e construção da base de dados}

Neste trabalho usaremos patentes como medida de atividade tecnológica. Os dados de patentes utilizados neste trabalho são oriundos do Instituto Nacional de Propriedade Industrial (INPI) e referem-se ao período 1999-2001. O número de patentes de cada município será normalizado pelo seu número de habitantes, seguindo a literatura da área. (Moreno et al., 2004; Carlino et al., 2001).

Muitos determinantes da atividade tecnológica são considerados pela literatura internacional. Dentre eles, podem ser citados: densidade e escala urbana, capacidade de pesquisa universitária, mercado de trabalho qualificado, grau de industrialização, diversidade industrial, $\mathrm{P} \& \mathrm{D}$ empresarial, mercado consumidor, grau de competição da economia local, amenidades culturais e transbordamentos de conhecimento.

Para testar a influência de cada um destes fatores sobre a inovação em Minas Gerais utilizaremos os seguintes indicadores:

População: refere-se ao número de residentes do município, segundo o Censo de 2000. (IBGE, 2002a). Este indicador tem a finalidade de medir o tamanho da cidade, sendo usado tradicionalmente para medir economias de urbanização. (Moreno et al., 2004).

Densidade de Emprego: é resultante da divisão do número de pessoas ocupadas pela área do município, em km². Benko (1999) afirma que "a fertilização cruzada só é possível num meio denso." Tal como em Carlino et al. (2001), este indicador foi usado para captar a influência da grande concentração espacial de empregados de funções semelhantes e/ou diferentes.

Renda: corresponde à soma dos rendimentos provenientes do trabalho, de transferências governamentais e de outras fontes, conforme estimativa do Atlas do Desenvolvimento Humano - 2000, do Programa das Nações Unidas para o Desenvolvimento (PNUD), disponível no sítio do IPEA. (IPEA, 2004a). Este indicador objetiva medir a magnitude do mercado consumidor local.

Amenidades Culturais: são representadas pelo número de cinemas, teatros e museus. Embora reflitam apenas parte dos componentes para a existência de boas condições de vida num centro urbano, acreditamos que haja forte relação entre ambos e, por conseguinte, indique o grau de atração do centro urbano. Vários trabalhos já argumentaram a favor das amenidades urbanas e culturais 
no desenvolvimento tecnológico (Markusen et al., 1986; Benko, 1999). Os dados são provenientes do IBGE. (IBGE, 2002a).

Qualificação da População: é medida pela porcentagem de pessoas com 25 anos de idade ou mais que possuíam mais de onze anos de estudo no município, segundo dados do IPEA (2004b). Esperamos que quanto maior for o nível educacional da população, maior será sua capacidade para criar e aplicar novos conhecimentos para fins econômicos. (Carlino et al., 2001; Sternberg e Arndt, 2001).

Grau de Industrialização: corresponde à relação entre o número total de pessoas ocupadas na indústria de transformação e o número total de pessoas ocupadas no município. Esta variável é usada por Sternberg e Arndt (2001) e Carlino et al. (2001) porque tem a função de controlar o fato de que a indústria, em relação a outros setores da economia, é o setor em que mais provavelmente surja uma patente. Os dados são referentes ao Cadastro Central de Empresas do IBGE de 1998. (IBGE, 2002a).

Grau de Especialização Industrial: é avaliado por meio do índice de Herfindahl, que é calculado por meio da soma dos quadrados da participação de cada setor no emprego industrial do município. Como este índice varia entre 0 e 1 , a especialização máxima possível, ou especialização num único setor industrial, seria representada pelo seu valor unitário. Quanto mais próximo de zero, maior é o grau de diversidade industrial existente no município. Utilizamos dados de emprego da Relação Anual de Informações Sociais - RAIS - de 1998, desagregados em 22 setores industriais da Classificação Nacional de Atividades Econômicas a dois dígitos do IBGE. (RAIS, 2000). A inclusão deste indicador seguiu sugestão de Carlino et al. (2001). Os dados da RAIS consideram apenas o mercado de trabalho formal. Logo, setores industriais que utilizam mão-de-obra informal não podem ser contabilizados na avaliação do grau de especialização industrial. Entretanto, acreditamos que isto não compromete a qualidade de nossa medida de especialização, pois o emprego informal ocorre em menor extensão no setor industrial.

Grau de Concentração Econômica: medido pelo porcentual de pessoas ocupadas, que eram assalariadas, nas quatro maiores empresas atuantes da unidade territorial. Este indicador também é conhecido como razão de concentração, sendo obtido no Cadastro Central de Empresas - 1998, do IBGE. (IBGE, 2002a). Este indicador é usado para avaliar o papel do grau de monopólio local e do nível de competição sobre a inovação. (Glaser et al., 1992; Carlino et al., 2001).

Capacidade de Realização de P\&D Universitário: medida pela quantidade de doutores em cursos de pós-graduação que possuem relevância em termos de possibilidade de criação e transferência de novas técnicas para o setor produtivo, devido à ausência de informações sobre gastos de P\&D realizados por universidades e instituições de pesquisa. Desta forma, foram considerados os docentes permanentes dos cursos de mestrado e doutorado das áreas de formação tecnológica, como Engenharias, Ciências Exatas e da Terra, Ciências Agrárias, Ciências Biológicas e da Saúde e Computação e Informática. Esta variável foi obtida por tabulação especial da CAPES, referente a 1999, e normalizada pela população de cada município. A motivação para a inclusão deste indicador está vinculada ao fato de haver fortes evidências de que a pesquisa universitária não só possui efeito positivo sobre as inovações, como é também um importante determinante da distribuição espacial das atividades de pesquisa empresariais. (Varga, 1998). Além disso, Jaffe (1989) destaca o efeito indireto da pesquisa universitária, a qual atrai $\mathrm{P} \& \mathrm{D}$ industrial e aumenta sua produtividade.

Capacidade de Realização de P\&D Industrial: os gastos de P\&D estão disponíveis na Pesquisa Industrial de Inovação Tecnológica (PINTEC) do IBGE. Entretanto, a PINTEC não possui representatividade amostral em nível municipal, exceto para grandes empresas (mais que 500 empregados). Por isso, como fonte de evidência da realização de $\mathrm{P} \& \mathrm{D}$ no tecido industrial de um município 
serão utilizados o valor adicionado e o valor bruto da produção industrial de empresas que possuem duas características fundamentais: ter inovado em produto que fosse novo para o mercado nacional e ser exportadora com preço-prêmio de 30\%. Este valor adicionado é oriundo da regionalização da PINTEC, cujos detalhes metodológicos podem ser obtidos em Negri et al. (2004) e Lemos et al. (2005). Segundo estes autores, essas empresas "inovam, diferenciam produtos e possuem maior capacitação tecnológica", sendo a "ponta mais dinâmica da indústria e que tende a capturar parcela maior da renda gerada pela indústria." Desta forma, não restam dúvidas de que a presença deste tipo de firma no município revela grande capacidade de realizar $\mathrm{P} \& \mathrm{D}$ industrial. A segunda vantagem de usar esta proxy vincula-se a outra característica das firmas desta amostra: ser exportadora. Esta vantagem será explicada abaixo.

Inserção Externa: as exportações podem se tornar um valioso mecanismo de estímulo à inovação (Fransman, 1985) porque permitem que pressões competitivas estimulem a melhoria da qualidade de produtos e a redução de custos; criam oportunidades para o aprendizado internacional interfirmas; ampliam o mercado da firma, propiciando o aproveitamento de economias de escala e crescente divisão do trabalho; e geram maior capacidade de importação de melhores insumos, que aumentam a produtividade total da economia.

Força de Trabalho com Formação Tecnológica: este indicador é geralmente usado nos trabalhos que avaliam a intensidade tecnológica da indústria, ao lado de outros indicadores como a intensidade do gasto em P\&D ou o grau de sofisticação técnica do produto. (Malecki, 1997; Benko, 1999). Entretanto, Markusen et al. (1986) optam pela porcentagem de profissionais ligados às áreas tecnológicas como o melhor indicador. Para construir este indicador foram utilizados dados da RAIS de 1998 relativos aos empregados com formação em Física, Química, Engenharias, Análise de Sistemas e Programação de Computadores, os quais foram divididos pelo total de empregados do município naquele ano. (RAIS, 2000).

A maior parte dessas variáveis foi construída com dados de 1998 e 1999 para evitar problema de simultaneidade e amenizar as questões relativas à direção de causalidade, tendo em vista que as patentes são referentes ao período de 1999-2001. Este procedimento é empregado de forma generalizada na literatura. (Carlino et al., 2001; Pamukcu, 2003).

\subsection{Análise fatorial}

Trabalhar com muitos indicadores ao mesmo tempo pode dificultar a visualização das informações reveladas pela base de dados. Por isso, uma forma adequada de lidar com muitas variáveis é a aplicação da análise fatorial, que representa um meio de simplificar os dados por reduzir o número de variáveis.

Com a análise fatorial, procurou-se verificar até que ponto é possível condensar o conjunto de variáveis originais selecionadas em um menor número de fatores, que tornem mais fácil a identificação de padrões de relação entre indicadores relevantes para o desenvolvimento tecnológico, segundo literatura internacional.

Para implementar a análise fatorial, foi realizada a extração dos fatores iniciais pelo método de componentes principais. Nesse procedimento foram definidas as cargas fatoriais de cada variável, a raiz característica vinculada aos respectivos fatores e as proporções da variância total do conjunto de variáveis. Os escores fatoriais foram obtidos após o procedimento de rotação Varimax, que procurou minimizar o número de variáveis que têm elevado peso em um fator. Os escores fatoriais são calculados a partir da multiplicação da matriz de coeficientes fatoriais pela matriz de dados normalizados originais. (Manly, 1986; Johnson e Wichern, 1992). 
Segundo Pereira (1999), alguns critérios devem nortear a decisão sobre a adequação dos dados ao método. Primeiro, deve-se observar o valor da medida de adequação global da amostra, dado pelo teste de Kaiser-Meyer-Olkin (KMO), e a possibilidade de a matriz de correlação dos dados ser uma identidade, o que é fornecido pelo teste de esfericidade de Bartlett. Segundo, além da simples redução do número de variáveis efetuada pela técnica, a obtenção de fatores que podem ser interpretados coerentemente com a natureza do fenômeno sob questão é um critério relevante. Como será visto adiante, o conjunto de 11 variáveis pôde ser condensado em quatro fatores que dão conta de grande parte da variabilidade do conjunto original de variáveis, sendo esta, também, uma medida de ajuste do modelo à análise dos dados. Além disto, a interpretação desses fatores pôde ser realizada com relativa facilidade. Por tudo isso, o objetivo de usar os escores fatoriais em modelos de regressão, para evitar problemas de multicolinearidade, foi bem-sucedido.

\subsection{Análise exploratória de dados espaciais}

Para lidar com os efeitos espaciais de dependência e heterogeneidade espaciais usaremos esta técnica espacial, que serve como abordagem exploratória para descrever características da distribuição espacial de uma variável, especialmente padrões de associações espaciais (clusters espaciais). (Anselin, 1996; Le Gallo e Ertur, 2003).

Como medida de dependência usaremos o I de Moran, que é calculado como se segue: $I=\left(n / \Sigma_{i j} w_{i j}\right) \Sigma_{i j} w_{i j}\left(x_{i}-\mu\right) / \Sigma_{i}\left(x_{i}-\mu\right)^{2}$, no qual $n$ é o número de observações, $x$ é a variável analisada, $\mu$ é a média de $x, w_{i j}$ são os elementos da matriz de pesos espaciais e os subscritos $i$ e $j$ se referem aos pares de localizações.

A sua interpretação é feita da seguinte forma: se a estatística I de Moran é positiva e significativa, há evidências de autocorrelação espacial positiva e vice-versa. ${ }^{1}$ Seu valor será computado a partir da abordagem das permutações, que requer uma distribuição empírica para computar média e desvio padrão, ao contrário da abordagem que considera a existência de distribuição normal não-correlacionada para os dados, e da abordagem da "aleatorização" (randomization), que toma as observações como se elas fossem igualmente prováveis em cada localização.

Segundo Anselin (1992), a abordagem da permutação realiza um reordenamento aleatório dos valores observados sobre cada localização, calculando uma nova estatística I para cada amostra. O valor da estatística I de Moran é comparado com a distribuição artificial da estatística, sob a hipótese nula de ausência de associação espacial, o que significa ocorrência das observações em qualquer lugar com igual probabilidade. Por causa das permutações, os valores de probabilidade fornecidos devem ser vistos como níveis de pseudo-significância.

Ainda que o I de Moran seja muito útil para fornecer uma indicação de agrupamento global dos dados, esta medida precisa ser complementada por estatísticas locais. Os indicadores "LISA" ou "Moran Local" cumprem este objetivo, indicando a significância dos valores locais de agrupamentos espaciais e tendo soma proporcional ao indicador global.

Seguindo a notação de Varga (1998), sua fórmula pode ser expressa como:

$I_{i}=\left[\left(x_{i}-\mu\right) /\left(\Sigma_{i}\left(x_{i}-\mu\right)^{2} / n\right)\right] \sum_{j} w_{i j}\left(x_{j}-\mu\right)$, em que $I_{i}$ é o Moran Local para a observação $i$ e $n, x, \mu, w_{i j}$ seguem notação anterior. Ele avalia a significância dos agrupamentos espaciais locais, conhecidos como hot spots, e indica focos (pockets) de não estacionaridade espacial (localizações atípicas). De forma similar ao indicador I de Moran, o "Moran Local" pode ser visualizado no Mapa de Significância de Moran ou Mapa de Clusters.

1 Com distribuição aleatória dos dados, o valor esperado do I de Moran é igual a -[1/(n-1)], segundo Anselin (1992). 
As informações fornecidas por esta técnica exploratória fornecem fundamentação empírica para a construção de especificações de modelos econométricos espaciais.

\subsection{Econometria espacial}

Os modelos de econometria espacial lidam com duas violações das suposições dos modelos de regressão lineares padrão, que são os termos de erros correlacionados e variância não constante. Em outras palavras, procuram lidar com o tratamento da dependência espacial e da heterogeneidade espacial. Na dependência, os valores da variável dependente e/ou do termo de erro numa localização são correlacionados com o valor das observações de localizações próximas. A heterogeneidade pode ocorrer por causa de heteroscedasticidade ou por coeficientes que variam através do espaço. A heteroscedasticidade, por sua vez, pode ser devida à heterogeneidade regional ou à autocorrelação espacial. Diferentemente da dependência espacial, tal heterogeneidade espacial pode ser tratada com técnicas econométricas padrão. (Anselin, 1992).

Segundo Anselin (1999), há duas maneiras de incorporar dependência espacial no modelo de regressão linear padrão. Na primeira, introduz-se um regressor adicional na forma de uma variável dependente defasada espacialmente. Este é o modelo de defasagem espacial, apropriado para avaliação da existência e grau de interação espacial. Na segunda, incorpora-se a dependência espacial na estrutura de erro $\left(\mathrm{E}\left[\varepsilon_{\mathrm{i}} \varepsilon_{\mathrm{j}}\right] \neq 0\right)$. Este é o modelo de erro espacial, adequado para a correção de vieses introduzidos pela autocorrelação espacial, devido ao uso de dados espaciais.

De acordo com Anselin e Bera (1998), o modelo de defasagem espacial é formalmente apresentado como se segue:

$$
y=\rho W y+X \beta+\varepsilon,
$$

em que:

$y$ é um vetor de observações para variável dependente $\mathrm{Nx1}$;

$X$ é uma matriz de observações sobre variáveis explicativas (exógenas);

$\varepsilon$ é o vetor $\mathrm{Nx} 1$ do termo de erros;

$\rho$ é o parâmetro auto-regressivo espacial, que mede a influência média dos vizinhos sobre observações no vetor $y$, indicando a proporção da variação total em $y$ explicada pela dependência espacial;

$\beta$ é o vetor Kx1 de coeficientes de regressão; e

$W y$ é o termo de defasagem espacial, que é correlacionado com os distúrbios, mesmo quando estes são independentes e identicamente distribuídos. Essa correlação com os distúrbios é diferente do que ocorre nas séries temporais, em que $y_{t-1}$ não é correlacionado com $\varepsilon_{t}$ na ausência de correlação serial nos erros. Na econometria espacial, $(W y)_{i}$ é sempre correlacionado com $\varepsilon_{i}$, a despeito da estrutura de correlação dos erros.

Desta forma, o termo de defasagem espacial deve ser tratado como variável endógena e métodos apropriados de estimação devem levar em conta tal endogeneidade, pois o uso dos mínimos quadrados ordinários (MQO) resultará em estimadores viesados e inconsistentes.

Especificar um processo espacial para os termos dos erros é a segunda forma de incorporar a autocorrelação espacial no modelo de regressão. Neste caso, Anselin (1999) afirma que a covariância dos erros resultante será não-esférica. Assim, os elementos que estão fora da diagonal da matriz 
de covariância expressarão a estrutura da dependência espacial e o método de mínimos quadrados ordinários será ineficiente, embora ainda não viesado.

De acordo com Anselin e Bera (1998), a especificação mais comum para o processo espacial auto-regressivo é a seguinte: $y=X \beta+\varepsilon$, sendo que $\varepsilon=\lambda W \varepsilon+\xi$, em que:

$\lambda$ é o coeficiente auto-regressivo espacial para a defasagem de erro $W \varepsilon$, para distinguir da notação do coeficiente espacial auto-regressivo $\rho$ no modelo de defasagem espacial; e

$\xi$ é o termo de erro não-correlacionado e homoscedástico.

De forma alternativa, pode-se expressar esta estrutura como:

$y=X \beta+(I-\lambda W)^{-1} \xi$

A covariância do erro será igual à expressão abaixo:

$E\left[\varepsilon \varepsilon^{\prime}\right]=\sigma^{2}(I-\lambda W)^{-1}\left(I-\lambda W^{\prime}\right)^{-1}=\sigma^{2}\left[(I-\lambda W)^{\prime}(I-\lambda W)\right]^{-1}$, que é uma estrutura idêntica para a variável dependente no modelo de defasagem espacial. O processo de erro auto-regressivo espacial conduz a uma covariância de erro não-zero entre cada par de observações, mas decrescentes em magnitude com a ordem de contigüidade.

No nosso caso, usaremos o método de MQO disponível no programa SpaceStat 1.91 e interpretaremos os seus testes de diagnóstico sobre normalidade dos erros (Jarque-Bera), heteroscedasticidade (Breusch-Pagan ou Koenker-Basset), dependência espacial (I de Moran e Multiplicadores de Lagrange - LM - para erro (LM-ERRO) e defasagem espacial (LM-LAG) ou para os dois ao mesmo tempo (LM-SARMA)), além do indicador de multicolinearidade ("multicollinearity condition number"). Detalhes estatísticos sobre como estes testes funcionam ou são construídos podem ser vistos em Anselin $(1992 ; 1995)$. Se os testes de dependência espacial forem significativos estatisticamente, serão implementadas estimações do modelo usando os métodos econométricos que tratam da dependência espacial, seja na forma de erro ou defasagem espacial, conforme os resultados dos testes mencionados acima.

Os critérios de decisão para escolha da especificação final seguem a abordagem clássica ("do modelo específico para o geral"), a qual pode ser resumida como segue (Florax et al., 2003): 1) estimação do modelo de regressão sem termos espaciais por meio de MQO; 2) teste da hipótese de ausência de dependência espacial devido à omissão de termos espaciais (defasagem espacial ou erros auto-regressivos espaciais) por meio dos testes LM-ERRO e LM-LAG; 3) caso sejam significativos, estimação da especificação mais adequada, segundo o teste que é mais significativo estatisticamente; 4) se LM-ERRO for significativo e LM-LAG não, estimação do modelo de erros espaciais, e vice-versa.

A abordagem clássica também pode ser combinada com os testes LM robustos, o que é chamado de abordagem híbrida pelos autores. Tanto a abordagem clássica quanto a híbrida são as mais indicadas relativamente à estratégia de Hendry ("abordagem geral para específica"), por causa do peso computacional desta e do fato de que a dependência espacial é mais uma regra que uma exceção nos dados espaciais.

\section{ANÁlise dos RESUltados}

As seções seguintes terão como objetivo: 1) realizar uma análise exploratória espacial da variável que é objeto de explicação nas regressões, ou seja, patentes per capita; 2) tratar as variáveis 
independentes do estudo por meio de técnica multivariada (análise fatorial), a fim de condensar o conjunto de indicadores selecionados a partir da revisão da literatura e estabelecer padrões de relação entre eles; 3) modelar a atividade tecnológica do Estado de Minas Gerais a partir dos dois resultados obtidos anteriormente.

\subsection{Análise exploratória de dados espaciais}

O propósito desta seção é explorar as características espaciais da variável dependente deste estudo, que é patente per capita. Com essa técnica podemos detectar a existência de padrões de associação espaciais (clusters espaciais significativos) no Estado de Minas Gerais.

A Tabela 1 mostra os valores das estatísticas I de Moran com base em dois conceitos de vizinhança. ${ }^{2}$ Todos os coeficientes são significativos estatisticamente, o que indica existência de autocorrelação espacial positiva. Entretanto, como os valores da estatística são próximos de zero, isto indica baixa concentração espacial para os dados de patenteamento per capita. Ainda assim é possível afirmar que municípios com valores elevados de patentes per capita são vizinhos de outros municípios com valores semelhantes para esta variável (e vice-versa).

Tabela 1 - Indicador global de autocorrelação espacial para patentes per capita por municípios de Minas Gerais

\begin{tabular}{|c|c|c|c|c|}
\hline Matriz de Pesos & I de Moran & Média & Desvio Padrão & Probabilidade* \\
\hline Queen & 0,0458 & $-0,0012$ & 0,0206 & 0,0254 \\
\hline 5 vizinhos mais próximos & 0,053 & $-0,001$ & 0,0203 & 0,0155 \\
\hline 10 vizinhos mais próximos & 0,0486 & $-0,001$ & 0,0144 & 0,0025 \\
\hline 15 vizinhos mais próximos & 0,0485 & $-0,001$ & 0,0117 & 0,0007 \\
\hline 20 vizinhos mais próximos & 0,0372 & $-0,001$ & 0,0101 & 0,0016 \\
\hline
\end{tabular}

*Pseudo-significância empírica baseada em 10.000 permutações.

Fonte: elaboração própria com base no programa SpaceStat.

Ainda que este indicador global tenha sua utilidade, é preciso calcular estatísticas de autocorrelação espacial locais (LISA) para avaliar o grau em que a atividade tecnológica do Estado é realmente concentrada. Elas levam em conta a significância estatística dos agrupamentos espaciais, permitindo concluir se um agrupamento existente é ou não estatisticamente significativo.

A Figura 1 é conhecida como Mapa de Clusters, o qual permite visualizar os regimes espaciais da atividade tecnológica de Minas Gerais que são estatisticamente significativos. ${ }^{3}$ As evidências apontam a existência de agrupamento espacial do tipo Alto-Alto apenas na região central do Estado, ao redor da área metropolitana de Belo Horizonte. A região formada por estes municípios possui condições para compartilhar e internalizar possíveis transbordamentos tecnológicos.

2 Usaremos dois conceitos de vizinhança. No primeiro, esta é definida a partir do conceito de contigüidade binária. Neste, são consideradas as interações espaciais existentes apenas entre os municípios que apresentam fronteira comum (critério Queen). O segundo é o conceito dos $k$ vizinhos mais próximos, em que a matriz de pesos espaciais é construída a partir da distância do grande círculo entre os centróides dos municípios. Construímos 4 matrizes baseadas neste conceito, estabelecendo $k$ igual a 5 , 10, 15 e 20. (Anselin, 1992).

3 Este mapa utiliza a matriz de pesos com base no critério Queen. Os mapas produzidos com os outros critérios da Tabela 1 são similares. 
Figura 1 - Mapa de clusters para Minas Gerais - patentes per capita

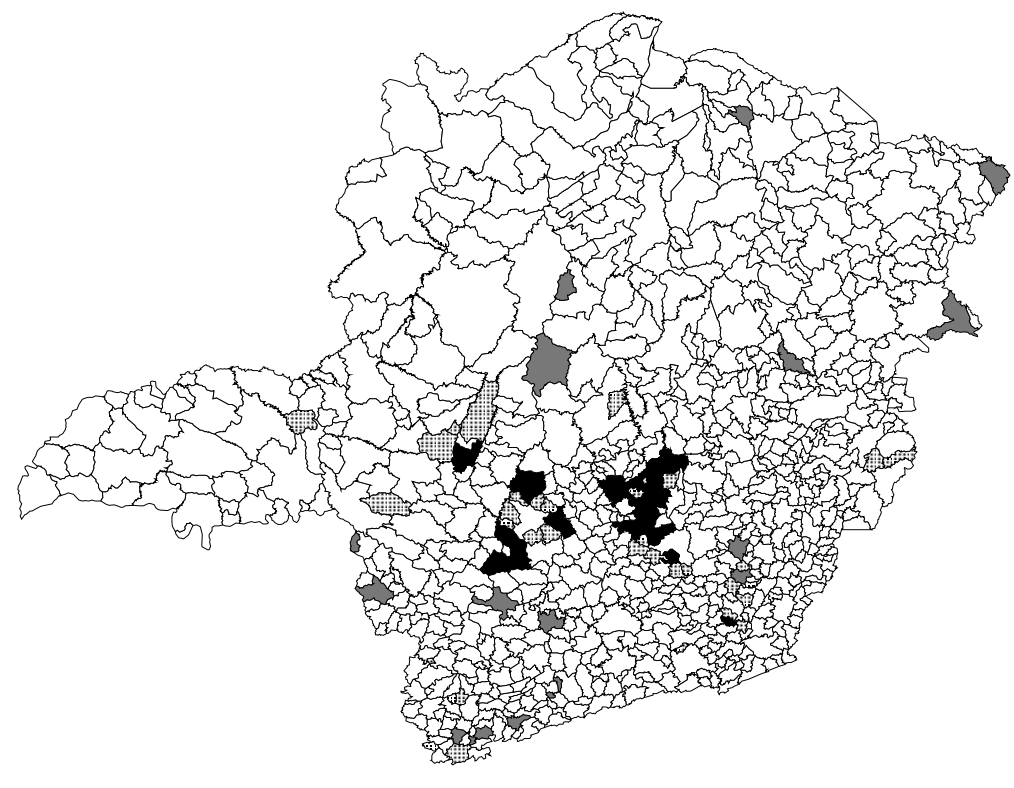

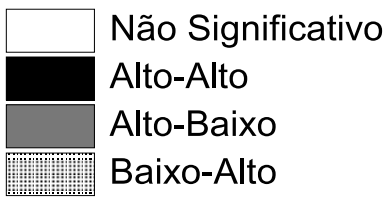

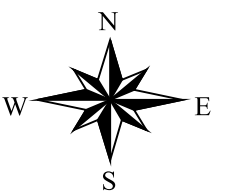

Fonte: elaboração própria com base no programa ArcView-GIS.

Além de mostrar o grau de desigualdade da atividade tecnológica do Estado, o Mapa de Clusters reforça a importância dos atributos urbanos (metropolitanos) para o desenvolvimento tecnológico, especialmente no caso de Minas Gerais, que possui uma estrutura urbana não integrada e caracterizada pelo elevado número de pequenas cidades que não possuem infra-estruturas urbana e tecnológica favoráveis ao desenvolvimento tecnológico mais equilibrado. A preponderância da região metropolitana de Belo Horizonte é coerente com o desequilíbrio da estrutura urbana dos estados brasileiros, mais polarizada que no caso norte-americano. (Ruiz, 2004).

Como se pode notar, outras áreas do Estado, classificadas como agrupamentos espaciais Alto-Baixo, estão dispersas geograficamente, refletindo a fragilidade do sistema estadual de inovação. Além disso, algumas delas apenas se destacam como regiões do tipo Alto-Baixo, por causa da ausência de atividade tecnológica dos seus vizinhos contíguos. A maior parte do Estado possui atividade tecnológica não significativa estatisticamente ou não possui nenhum registro de patente (área branca do mapa).

A próxima seção tem o objetivo de tratar e preparar as variáveis independentes para a seção que tenta modelar os determinantes da atividade inovadora.

\subsection{Análise fatorial ${ }^{4}$}

As Tabelas 2, 3 e 4 mostram os resultados da análise fatorial aplicada sobre 14 indicadores que representam as variáveis descritas na seção 2.1, abrangendo 853 municípios mineiros. A medida de adequação geral da amostra (KMO) situa-se em torno de 0,70 , indicando um bom grau de ajuste

4 Os procedimentos metodológicos desta seção seguem Johnson e Wichern (2002). 
entre as variáveis e o método. O teste de Bartlett rejeita a hipótese nula de que a nossa matriz de correlação entre as variáveis seja uma matriz identidade (Tabela 2).

Tabela 2 - Testes de adequação da amostra à análise fatorial

\begin{tabular}{lr}
\hline Medida de Adequação da Amostra de Kaiser-Meyer-Olkin & 0,7000 \\
\hline Teste de Esfericidade de Bartlett & \\
Estatística $\chi^{2}$ & $18.537,61$ \\
Graus de liberdade & 91 \\
Probabilidade & 0,000 \\
\hline
\end{tabular}

Fonte: elaboração própria com base no programa SPSS 11.5.

Tabela 3 - Raízes características e porcentual de variância explicada pelos fatores

\begin{tabular}{cccc}
\hline Fatores Extraídos & Raízes Características & Variância (\%) & Variância Acumulada (\%) \\
\hline 1 & 4,758 & 33,98 & 33,98 \\
2 & 3,362 & 24,02 & 58,00 \\
3 & 2,154 & 15,39 & 73,39 \\
4 & 1,052 & 7,52 & 80,90 \\
\hline
\end{tabular}

Fonte: elaboração própria com base no programa SPSS 11.5.

Tabela 4 - Comunalidades dos indicadores selecionados

\begin{tabular}{lc}
\hline Variáveis & Comunalidades \\
\hline Amenidades Culturais & 0,8098 \\
Capacidade de Pesquisa Universitária & 0,7299 \\
Densidade de Emprego & 0,9198 \\
Escolaridade da População Adulta & 0,7458 \\
Especialização Industrial (Índice de Herfindahl) & 0,6450 \\
Exportações de Empresas Dinâmicas & 0,9828 \\
Força de Trabalho com Formação Tecnológica & 0,3177 \\
Grau de Concentração Econômica (CR4) & 0,7390 \\
Grau de Industrialização & 0,5492 \\
Importações de Empresas Dinâmicas & 0,9660 \\
População & 0,9649 \\
Renda & 0,9794 \\
Valor Adicionado por Empresas Dinâmicas & 0,9808 \\
Valor Bruto da Produção de Empresas Dinâmicas & 0,9965 \\
\hline
\end{tabular}

Fonte: elaboração própria com base no programa SPSS 11.5.

A partir do uso do método de rotação ortogonal varimax foi possível extrair quatro fatores que possuem raízes características superiores à unidade. Eles explicam $81 \%$ da variabilidade total dos 14 indicadores selecionados (Tabela 3). Isto significa que a perda de informação é de apenas 19\%, ao mesmo tempo que a complexidade do banco de dados é reduzida substancialmente, pois em vez de 14 indicadores, poderemos trabalhar com quatro. 
A Tabela 4 mostra as comunalidades, que descrevem a quantidade de variância levada em consideração por cada variável. Quando são altas, como na maioria mostrada, indicam que os componentes extraídos representam bem a variável. A pior representação ocorre para a variável "Força de Trabalho com Formação Tecnológica”. Em seguida, temos a variável “Grau de Industrialização” com comunalidade de 0,55 . Neste caso, porém, mais da metade de sua variância é reproduzida pelos fatores comuns.

A Tabela 5 apresenta as cargas fatoriais. $\mathrm{O}$ valor de cada coeficiente da tabela resume a relação existente entre cada uma das variáveis e os respectivos fatores. É importante notar que a rotação dos fatores foi bem-sucedida, pois cada variável apresenta forte relação com apenas um fator, o que facilita sua interpretação. Apenas foram apresentados os coeficientes com valor acima de 0,50, para facilitar a visualização e a interpretação dos resultados.

Tabela 5 - Matriz de componentes após rotação varimax

\begin{tabular}{|c|c|c|c|c|}
\hline \multirow{2}{*}{ Variáveis } & \multicolumn{4}{|c|}{ Fatores } \\
\hline & 1 & 2 & 3 & 4 \\
\hline Amenidades Culturais & & 0,8500 & & \\
\hline Capacidade de Pesquisa Universitária & & & & 0,8320 \\
\hline Densidade de Emprego & & 0,9570 & & \\
\hline Escolaridade da População Adulta & & & 0,7520 & \\
\hline Especialização Industrial (Índice de Herfindahl) & & & $-0,8020$ & \\
\hline Exportações de Empresas Dinâmicas & 0,9900 & & & \\
\hline \multicolumn{5}{|l|}{ Força de Trabalho com Formação Tecnológica } \\
\hline Grau de Concentração Econômica (CR4) & & & $-0,8390$ & \\
\hline Grau de Industrialização & & & 0,6770 & \\
\hline Importações de Empresas Dinâmicas & 0,9800 & & & \\
\hline População & & 0,9650 & & \\
\hline Renda & & 0,9870 & & \\
\hline Valor Adicionado por Empresas Dinâmicas & 0,9950 & & & \\
\hline Valor Bruto da Produção de Empresas Dinâmicas & 0,9800 & & & \\
\hline
\end{tabular}

Fonte: elaboração própria com base no programa SPSS 11.5.

O primeiro fator, que leva em consideração cerca de $34 \%$ da variância de todas as variáveis (Tabela 3), é mais altamente correlacionado com as variáveis vinculadas às "Empresas Dinâmicas" (Tabela 5). Desta forma, poderemos dar ao primeiro fator este nome (Fator 1: "Empresas Dinâmicas").

O segundo fator, que explica cerca de $24 \%$ da variabilidade total dos dados (Tabela 3), apresenta coeficientes de elevada magnitude e positivos. Pode-se denominar tal fator de "Escala Urbana” (Fator 2: "Escala Urbana”), porque todas as quatro variáveis - renda, população, densidade de emprego e amenidades culturais - são características de cidades de grande porte.

O terceiro fator, que representa $15 \%$ da variância total, opõe municípios com alto grau de concentração econômica e especialização industrial a outros que possuem alto grau de industrialização e porcentual elevado de pessoas adultas com mais de 11 anos de estudo (Tabela 5). Em outras palavras, os municípios muito industrializados apresentam diversificação setorial e população qualificada. O trade-off apresentado acima e o sinal negativo das variáveis com maior relação com este fator (CR4 e Índice de Herfindahl) permitem que ele seja denominado por "diversidade industrial e ausência de concentração econômica” (Fator 3: "Diversidade Industrial”). 
O quarto fator, que explica 7,5\% da variância (Tabela 2), possui forte relação com uma única variável, que é a quantidade de doutores per capita, proxy da capacidade de realizar pesquisa universitária (Tabela 4). Assim, este será o nome deste fator (Fator 4: "P\&D Universitário").

$\mathrm{Na}$ análise fatorial a ordem de importância dos fatores, em termos de capacidade de explicação da variância total, fornece informações relevantes, porque o primeiro fator é o que melhor explica a variabilidade do conjunto total de indicadores. Portanto, a presença de "Empresas Dinâmicas" é o principal fator em termos de caracterização e diferenciação dos municípios mineiros. Ele explica a variância quase $50 \%$ mais que o segundo fator considerado mais importante ("Escala Urbana”). A contribuição mais modesta (7,5\%) é a do fator "P\&D Universitário", o que é coerente com o número reduzido de municípios (apenas 9) que possuem doutores nas áreas relevantes selecionadas. ${ }^{5} \mathrm{Ou}$ seja, a grande maioria dos municípios não se diferencia em termos desta variável.

Na próxima seção, os escores fatoriais obtidos nesta etapa serão usados nas regressões e as variáveis independentes serão classificadas de acordo com esta seção.

\subsection{Econometria espacial}

A Tabela 6 mostra os resultados obtidos pelo método dos mínimos quadrados ordinários, como primeira tentativa de modelar a atividade tecnológica dos municípios de Minas Gerais. Esta Tabela é dividida em três partes. Na primeira, mostram-se os coeficientes estimados, seus desvios padrão, estatísticas $t$ e valor de probabilidade. Na segunda, apresentam-se os testes para normalidade dos erros e heteroscedasticidade, além do indicador de multicolinearidade e do grau de ajuste do modelo. Na terceira, encontram-se os testes de diagnóstico para dependência espacial.

Tabela 6 - Regressão por MQO e testes de diagnóstico para dependência espacial

\begin{tabular}{|c|c|c|c|c|}
\hline Variáveis Independentes & Coeficiente & Desvio Padrão & $t$ & Probabilidade \\
\hline Constante & 0,0818 & 0,0075 & 10,82 & 0,0000 \\
\hline Empresas Dinâmicas & 0,0300 & 0,0075 & 4,01 & 0,0001 \\
\hline Escala Urbana & 0,1416 & 0,0075 & 18,88 & 0,0000 \\
\hline Diversidade Industrial & 0,0989 & 0,0075 & 13,10 & 0,0000 \\
\hline P\&D Universitário & 0,0498 & 0,0075 & 6,65 & 0,0000 \\
\hline R_POS & 2,1861 & 0,0556 & 39,31 & 0,0000 \\
\hline $\mathrm{R}^{2}$ (ajustado) & 0,7292 & & & \\
\hline Condição de Multicolinearidade & 1,1986 & & & \\
\hline Jarque-Bera & $77.367,39^{* * *}$ & & & \\
\hline Koenker-Basset & $116,17^{\star \star *}$ & & & \\
\hline White & $177,27^{\star \star *}$ & & & \\
\hline Moran & 1,8809 & - & - & 0,0599 \\
\hline LM (erro) & 3,2147 & $\cdot$ & $\cdot$ & 0,0730 \\
\hline LM robusto (erro) & 1,6364 & $\cdot$ & $\cdot$ & 0,2008 \\
\hline LM (lag) & 1,6348 & $\cdot$ & - & 0,2010 \\
\hline LM robusto (lag) & 0,0565 & $\cdot$ & $\cdot$ & 0,8120 \\
\hline LM (SARMA) & 3,2713 & $\cdot$ & - & 0,1948 \\
\hline
\end{tabular}

Nota: ${ }^{* *}$ Significativo a $1 \%$.

Obs.: $\mathrm{N}=853$; Variável Dependente: Patentes per capita.

Fonte: elaboração própria com base no programa SpaceStat 1.91.

5 Belo Horizonte, Viçosa, Lavras, Uberlândia, Ouro Preto, Itajubá, Juiz de Fora, Uberaba e Diamantina. 
O primeiro ponto a ser observado é que todos os coeficientes são altamente significativos e possuem coeficiente com valor positivo, como esperado. Em relação às variáveis independentes provenientes da análise fatorial, destaca-se a "escala urbana" por causa da magnitude de seu coeficiente. Este resultado revela que também no Estado de Minas Gerais as economias de urbanização exercem forte influência sobre a inovação, quando medida por patentes. Em seguida, temos a "diversidade industrial" como fator mais importante na determinação da atividade tecnológica. Desta forma, "escala urbana" e "diversidade industrial" são os atributos ausentes na grande maioria dos municípios mineiros, pois apenas 2,7\% (23) destes possuíam população superior a 100 mil habitantes no ano de 2000. Estes pequenos municípios possuem estrutura econômica concentrada, em que os quatro maiores estabelecimentos dominam maior parcela do emprego (CR4), e têm estrutura industrial especializada.

A presença de "empresas dinâmicas" no tecido industrial do município e de universidades com professores qualificados em áreas relevantes para indústria também se apresentam como determinantes significativos da atividade tecnológica mineira, embora sejam menos importantes que os dois fatores anteriormente citados. Isto reflete, em parte, a fragilidade do sistema de inovação nacional, traduzida por Albuquerque et al. (2002) como imaturidade e concentração.

A imaturidade ocorre por causa da estrutura industrial brasileira, marcada por setores de baixa e média intensidade tecnológica. Isto se reflete no baixo peso dos gastos de $\mathrm{P} \& \mathrm{D}$ em relação aos gastos totais com inovação no Brasil $(16,8 \%)$ e em uma elevada participação dos gastos com máquinas e equipamentos $-52,1 \%$. (IBGE, 2002b). ${ }^{6} \mathrm{O}$ peso deste tipo de atividade inovadora claramente confirma a condição de atraso tecnológico do País e reflete a característica de "absorção passiva" destacada por Viotti (2002).

A concentração se deve ao peso do Estado de São Paulo no que se refere à atividade produtiva e tecnológica. O Estado concentrava, em 1998, cerca de 42\% dos doutores em instituições de ensino e cerca de um terço dos alunos e instituições de ensino superior, assim como do número de alunos dos programas de pós-graduação vinculados a áreas de formação tecnológica. (Diniz e Gonçalves, 2000). Segundo Albuquerque (2003), 48,7\% das patentes depositadas no INPI, referentes ao período 1990-2000, eram do Estado de São Paulo.

Outra variável significativa, incluída entre os regressores, foi a dummy R_POS, que foi adicionada para controlar observações discrepantes da amostra, em vez de se retirar tais municípios do exercício econométrico. ${ }^{7}$ A sua inclusão obedeceu ao seguinte critério: ordenamos os resíduos obtidos num primeiro modelo que utilizava apenas as quatro variáveis independentes e criamos a dummy para aqueles que apresentavam resíduo maior que três desvios padrão. ${ }^{8}$ No caso destes municípios, as variáveis independentes consideradas pelo modelo não são capazes de explicar sua performance tecnológica. Se somados, eles registraram 127 dos 1.422 depósitos de patentes do período 1999-2001. Fatores exógenos ao modelo, como espírito criativo e empreendedor e especialização no setor mobiliário, como é o caso de Ubá, devem ser relevantes para explicar tal atividade tecnológica, uma vez que os fatores usados no modelo não são suficientes para explicá-los.

A segunda parte da Tabela 6 mostra que o grau de ajuste do modelo é relativamente alto (73\%) e que os resíduos não são normais, uma vez que a estatística Jarque-Bera é significativa a $1 \%$, sendo capaz de rejeitar a hipótese nula de normalidade. Por causa do uso da análise fatorial,

6 O restante dos gastos com inovação no Brasil é dividido da seguinte forma: 14,8\% com projeto industrial e outras preparações técnicas, 6,4\% com a introdução das inovações tecnológicas no mercado, 5,2\% com a aquisição de outros conhecimentos externos, $2,8 \%$ com a aquisição externa de $\mathrm{P} \& \mathrm{D}$ e $1,9 \%$ com o treinamento.

7 Esta variável dummy para controlar outliers não influencia qualitativamente os resultados do modelo.

8 Dezesseis municípios foram considerados outliers por este critério: Salto da Divisa, São Geraldo, Ubá, Presidente Juscelino, Santa Luzia, Ouro Preto, Aimorés, Pirapora, Santo Antônio do Monte, Liberdade, Matutina, Paraisópolis, Borda da Mata, Extrema, Claraval e Araxá. 
a condição de multicolinearidade está muito abaixo do nível máximo de tolerância sugerido em Anselin (1992), que é 30. Este indicador somente não possui valor unitário, que é o mínimo possível, por causa da inclusão da variável dummy. Os testes de Koenker-Basset e de White sugerem a ocorrência de heteroscedasticidade. Diante disso, as inferências realizadas anteriormente devem ser revistas sob novas estimações que levem em consideração desvios padrão corrigidos, para permitir uma inferência robusta. (Anselin, 1992).

Antes de procedermos a esta etapa de reestimação é preciso analisar a terceira parte da Tabela 6. Nenhum dos testes de especificação de dependência espacial, relativos à defasagem espacial, é significativo. Isto equivale a dizer que o patenteamento per capita dos vizinhos não é determinante significativo da atividade tecnológica de um município. Em outras palavras, não existem transbordamentos de conhecimento entre os municípios mineiros quando a atividade tecnológica é medida por patentes. Desta forma, os municípios que desenvolveram tecnologia no período 1999-2001 apresentaram-se como enclaves tecnológicos, sem interação espacial com os municípios contíguos. Este resultado é explicado pela existência de barreiras espaciais à difusão dos conhecimentos tecnológicos entre os municípios, como baixos índices de industrialização, de escolaridade superior da população, de doutores, de empregados com formação tecnológica, de diversidade industrial e tecnológica e altos níveis de concentração empresarial.

As barreiras espaciais guardam íntima conexão com a rede urbana do Estado. Ao contrário de São Paulo, o Estado de Minas Gerais não possui uma densa e complexa rede urbana, capaz de atrair atividades de alta tecnologia ou de absorver quaisquer transbordamentos de conhecimento tecnológico originados em municípios vizinhos. Naquele Estado, a rede de cidades de porte médio apresenta-se como alternativa de investimento para capitais que procuram outros sítios em razão de possíveis deseconomias de aglomeração da área metropolitana de São Paulo. Isto já ocorreu na experiência de reversão da polarização brasileira nas décadas de 1970 e 1980, em que os investimentos ficaram retidos nas proximidades de São Paulo, dando origem a um processo de desconcentração com extensão limitada, conforme descrito em Diniz (1993; 1999).

Há razões para supormos que a heteroscedasticidade constatada na Tabela 6 seja causada pela existência de dois regimes espaciais de atividade tecnológica no Estado de Minas Gerais, associados ao tamanho das cidades. Em outras palavras, se dividirmos o Estado de Minas Gerais em dois grupos de municípios provavelmente encontraremos coeficientes diferentes para as variáveis testadas. Assim, testaremos a hipótese nula de que os coeficientes são os mesmos em ambos os regimes espaciais, definido por uma variável indicadora. Esta assume valor unitário caso o município tenha população superior a 100 mil habitantes, que no caso de Minas Gerais constitui um grupo de apenas 23 municípios, segundo a divisão territorial de 2000, e assume valor zero se o município apresentar população menor. A possível instabilidade estrutural dos parâmetros será avaliada pelo teste de Chow.

A Tabela 7 contém os resultados da implementação do método de Mínimos Quadrados Generalizados Estimados (Feasible Generalized Least Squares - FGLS). Segundo Anselin (1992), o objetivo da estimação FGLS do modelo de erro heteroscedástico é obter estimativas consistentes para os elementos da variância do erro. Neste caso, dividimos o Estado de Minas Gerais em dois grupos de municípios de acordo com o tamanho de suas populações. Esta tabela é dividida em seis partes. Primeiro, vale notar que a estatística do teste de Chow é altamente significativa ( $5^{\mathrm{a}}$ parte), rejeitando a hipótese nula de que os coeficientes são iguais para o conjunto de cidades mineiras. Confirma-se,

9 Segundo Anselin (1992), há duas opções de estimações para o nosso caso. Na primeira, estima-se um modelo por MQO que leve em consideração a possibilidade de mudança estrutural no espaço. Na segunda, estima-se um modelo de erro heteroscedástico, em que a variável heteroscedástica é construída a partir de uma variável indicadora categórica. Ambos os modelos são estimados e mostram resultados convergentes e coerentes, sendo suficientes para lidar com o problema de heteroscedasticidade. Entretanto, apenas a segunda regressão é apresentada, embora o outro resultado também esteja à disposição sob requisição. 
deste modo, a existência dos dois regimes espaciais em Minas Gerais. Este procedimento também ajudou a controlar a heteroscedasticidade, tendo em vista o resultado do teste de Wald.

As cidades consideradas pequenas (abaixo de 100 mil habitantes) possuem coeficientes com nomes seguidos de 0 como sufixo. As cidades médias e grandes possuem sufixo 1 . No caso das primeiras, todos os fatores apresentam-se significativos a 1\%, com exceção de "empresas dinâmicas" (significativo a 3\%). No caso das cidades maiores, todos os fatores são altamente significativos e apresentam o sinal esperado, com exceção da constante e do fator "P\&D Universitário", que apresenta resultado contraintuitivo, por causa do sinal negativo. Além disto, sua significância estatística não é muito robusta $(8 \%)$, o que levanta suspeita a respeito de sua real influência sobre a atividade tecnológica. $\mathrm{Na} 4^{\mathrm{a}}$ parte da Tabela 7 nota-se que os municípios pequenos possuem coeficiente para a variância do erro igual a 0,0452, enquanto que os médios e grandes possuem variância igual a 0,0503.

\section{Tabela 7 - Modelo de erro heteroscedástico: estimação por FGLS}

\begin{tabular}{|c|c|c|c|c|}
\hline Variáveis Independentes & Coeficiente & Desvio Padrão & $\mathrm{t}$ & Probabilidade \\
\hline Constante_0 & 0,0951 & 0,0086 & 11,11 & 0,0000 \\
\hline Empresas Dinâmicas_0 & 0,1436 & 0,0644 & 2,23 & 0,0258 \\
\hline Escala Urbana_0 & 0,2916 & 0,0464 & 6,29 & 0,0000 \\
\hline Diversidade Industrial_0 & 0,0951 & 0,0078 & 12,19 & 0,0000 \\
\hline P\&D Universitário_0 & 0,0427 & 0,0075 & 5,69 & 0,0000 \\
\hline R_POS_0 & 2,2051 & 0,0565 & 39,06 & 0,0000 \\
\hline Constante_1 & $-0,0825$ & 0,1601 & $-0,52$ & 0,6061 \\
\hline Empresas Dinâmicas_1 & 0,0285 & 0,0094 & 3,02 & 0,0026 \\
\hline Escala Urbana_1 & 0,1422 & 0,0129 & 11,05 & 0,0000 \\
\hline Diversidade Industrial_1 & 0,3144 & 0,0927 & 3,39 & 0,0007 \\
\hline P\&D Universitário_1 & $-0,1748$ & 0,1013 & $-1,73$ & 0,0844 \\
\hline R_POS_1 & 1,4063 & 0,2405 & 5,85 & 0,0000 \\
\hline \multicolumn{5}{|c|}{ Estabilidade dos Coeficientes Individuais } \\
\hline Constante_0 & 1,2277 & - & - & 0,2679 \\
\hline Empresas Dinâmicas_0 & 3,1299 & - & - & 0,0769 \\
\hline Escala Urbana_0 & 9,6435 & - & - & 0,0019 \\
\hline Diversidade Industrial_0 & 5,5531 & - & - & 0,0184 \\
\hline P\&D Universitário_0 & 4,5849 & - & - & 0,0323 \\
\hline R_POS_0 & 10,4596 & - & - & 0,0012 \\
\hline \multicolumn{5}{|c|}{ Coeficientes Heteroscedásticos } \\
\hline Grande_0 & 0,0452 & 0,0022 & 20,37 & 0,0000 \\
\hline Grande_1 & 0,0503 & 0,0148 & 3,39 & 0,0007 \\
\hline $\mathrm{R}^{2}$ (ajustado) & 0,7431 & & & \\
\hline Wald & $0,1132^{\mathrm{NS}}$ & & & \\
\hline Chow - Wald & $38,4823^{* * *}$ & & & \\
\hline LM (erro) & 4,5428 & - & - & 0,0331 \\
\hline LM (lag) & 2,5434 & - & - & 0,1108 \\
\hline
\end{tabular}

Nota: NS $=$ Não Significativo; ${ }^{* *}$ Significativo a $1 \% ; * *$ Significativo a $3 \%$.

Obs.: $\mathrm{N}=853$; Variável Dependente: Patentes per capita.

FGLS = Feasible Generalized Least Squares (Mínimos Quadrados Generalizados Estimados).

Fonte: elaboração própria com base no programa SpaceStat 1.91. 
O resultado contra-intuitivo referente ao "P\&D Universitário" pode estar associado a um traço do sistema nacional de inovação brasileiro, que é a falta de conexão entre a produção científica e a atividade tecnológica (Albuquerque et al., 2002), especialmente no caso de Minas Gerais, em que já fora constatada a predominância de patentes em setores de baixa tecnologia ou na classe tecnológica conhecida como "escala-intensiva". (Silva et al., 2000). Isto tornaria a presença da capacidade de realizar pesquisas universitárias menos importante para o atual estágio tecnológico do Estado.

Em relação às cidades pequenas, a relação entre "P\&D Universitário" e patentes per capita parece ser mais robusta. Neste caso, as universidades podem estar funcionando como âncoras do sistema local de pesquisa, exercendo diretamente um papel de liderança na atividade tecnológica ou indiretamente por meio de transbordamentos de conhecimento intramunicipais, especialmente em Viçosa, Lavras, Ouro Preto e Itajubá.

Outros dois resultados, que dizem respeito à magnitude dos coeficientes das variáveis "Empresas Dinâmicas" e "Escala Urbana” dos dois grupos de municípios, precisam de explicações. Constata-se, em ambos os casos, que seus coeficientes são maiores para os municípios pequenos, em relação aos municípios grandes (acima de 100 mil habitantes). A ordem de importância das variáveis nos dois grupos de municípios é consideravelmente diferente, o que se deve às seguintes razões:

1) No primeiro grupo de municípios, o tamanho urbano é o principal fator a influenciar a atividade tecnológica. Coerentemente com a expectativa teórica, isto significa que existe um limiar a partir do qual a atividade tecnológica ocorre com mais probabilidade no município. Ou seja, municípios muito pequenos não possuem atividade tecnológica significativa. ${ }^{10} \mathrm{O}$ segundo fator que mais importa para explicar a atividade tecnológica nos municípios deste primeiro grupo é a presença de empresas dinâmicas, que podem ser vistas como âncoras econômicas e tecnológicas da economia local.

2) No segundo grupo de municípios, a diversidade industrial é o principal fator a influenciar a atividade tecnológica, de acordo com a tese de Jacobs (1969). Este resultado reforça a importância do ambiente urbano como aquele em que há melhores condições para o surgimento de inovações. Ademais, isto significa que quando os municípios atingem determinado tamanho (no nosso caso, 100 mil habitantes), a variável escala urbana deixa de ser o fator preponderante para explicar a atividade tecnológica e outros fatores passam a assumir maior importância na explicação da atividade tecnológica, que no presente caso é a diversidade industrial.

A $6^{\mathrm{a}}$ parte da tabela mostra os testes de diagnóstico para dependência espacial. Os dois testes realizados pelo programa sugerem a incorporação de um termo de erro espacial no modelo, tendo em vista o resultado do teste do Multiplicador de Lagrange, que detectou a presença de dependência espacial do erro por meio da matriz espacial de pesos usada (Queen). Esse diagnóstico significa que aqueles fatores não modelados na regressão são espacialmente correlacionados.

Como esforço final de estimação, apresentamos a Tabela 8.

Nesta tabela usamos um modelo de erro espacial estimado pelo Método Generalizado dos Momentos (GM) em dois estágios, uma vez que todos os modelos tiveram indícios de não normalidade dos erros. (Anselin, 1999).

10 Existem apenas oito municípios patenteadores (com 10 patentes) dentro do conjunto de 514 municípios com menos de 10 mil habitantes em Minas Gerais. 
Tabela 8 - Modelo de erro espacial pelo método GM - 2 estágios

\begin{tabular}{lcccc}
\hline Variáveis Independentes & Coeficiente & Desvio Padrão & t & Probabilidade \\
\hline Constante_0 & 0,0935 & 0,0097 & 9,68 & 0,0000 \\
Empresas Dinâmicas_0 & 0,1388 & 0,0565 & 2,46 & 0,0141 \\
Escala Urbana_0 & 0,2469 & 0,0459 & 5,38 & 0,0000 \\
Diversidade Industrial_0 & 0,0969 & 0,0081 & 12,02 & 0,0000 \\
P\&D Universitário_0 & 0,0444 & 0,0075 & 5,92 & 0,0000 \\
R_POS_0 & 2,2110 & 0,0561 & 39,42 & 0,0000 \\
\hline Constante_1 & $-0,1090$ & 0,1669 & $-0,65$ & 0,5140 \\
Empresas Dinâmicas_1 & 0,0288 & 0,0089 & 3,24 & 0,0012 \\
Escala Urbana_1 & 0,1419 & 0,0121 & 11,70 & 0,0000 \\
Diversidade Industrial_1 & 0,3206 & 0,0898 & 3,57 & 0,0004 \\
P\&D Universitário_1 & $-0,1744$ & 0,1013 & $-1,72$ & 0,0849 \\
R_POS_1 & 1,3928 & 0,2268 & 6,14 & 0,0000 \\
\hline LAMBDA & 0,1224 & 0,0000 & 0,00 & 0,0000 \\
\hline Estabilidade dos Coeficientes Individuais & & & - & 0,2260 \\
Constante_0 & 1,4660 & - & - & 0,0546 \\
Empresas Dinâmicas_0 & 3,6935 & - & - & 0,0269 \\
Escala Urbana_0 & 4,8964 & 6,1581 & - & 0,0131 \\
Diversidade Industrial_0 & 4,6461 & - & 0,0311 \\
P\&D Universitário_0 & 12,2603 & - & 0,0005 \\
R_POS_0 & 0,7429 & - & - \\
\hline R (buse) & $35,5471^{* * *}$ & & - & - \\
Chow - Wald & & - & - \\
\hline
\end{tabular}

Nota: ${ }^{* *}$ Significativo a $1 \%$.

Obs.: N= 853; Variável Dependente: Patentes per capita.

$\mathrm{GM}=$ Generalized Moments (Método Generalizado dos Momentos).

Fonte: elaboração própria com base no programa SpaceStat 1.91.

Também consideramos os dois regimes espaciais de inovação de Minas Gerais. Em relação às tabelas anteriores, os resultados são qualitativamente os mesmos, embora as estimativas estejam corrigidas para a dependência espacial do erro. Note que o parâmetro $\lambda$ é considerado um termo de distúrbio (nuisance) e não há inferência sobre ele, desde que não possui estimativa de desvio padrão, estatística $t$ e valor de probabilidade. ${ }^{11}$

\section{CONCLUSÕES E SUGESTÕES DE POLÍTICAS PÚBLICAS}

Este trabalho constatou que a atividade tecnológica de Minas Gerais é concentrada espacialmente ao redor da área metropolitana de Belo Horizonte. Esta área forma um tipo de cluster (Alto-Alto) que é o mais relevante em termos de potencial econômico e tecnológico porque revela

11 Embora não seja apresentado aqui, o modelo de erros espaciais também foi estimado por meio das outras duas opções do programa SpaceStat, que são Método Generalizados dos Momentos Iterado e Groupwise Heteroskedasticity. Os resultados são análogos e qualitativamente similares. 
a existência de transbordamentos de conhecimento entre os municípios e, possivelmente, complementaridade produtiva, sendo que o dinamismo tecnológico de um está intimamente associado ao dos outros. Outros clusters do tipo Alto-Baixo também foram detectados de forma esparsa pelo Estado, assemelhando-se a ilhas tecnológicas.

Para fins de modelagem econométrica, a análise exploratória de dados espaciais sugeriu o peso dos atributos urbanos para inovar, especialmente as economias de urbanização disponíveis na região metropolitana de Belo Horizonte. No caso de Minas Gerais, a estrutura urbana é mais desequilibrada que a do Sul do País ou em relação à de São Paulo. Isto impõe sérias limitações a um processo de desenvolvimento tecnológico menos concentrado.

Os modelos econométricos confirmam a dependência que a inovação possui em relação aos atributos urbanos e industriais. A escala urbana afetou positivamente o patenteamento per capita, assim como o grau de diversidade industrial do município. A presença de empresas que diferenciam seus produtos e que possuem intensa inserção externa ("empresas dinâmicas") é um elemento que potencializa a inovação, coerentemente com os argumentos da literatura internacional sobre o papel da exportação e importação. O único resultado que não ocorreu como esperado foi o relativo à capacidade de realizar pesquisas universitárias em áreas relevantes para a indústria, no caso de municípios maiores que 100 mil habitantes. Neste grupo, pode ser que o tecido industrial existente nestas cidades não esteja aproveitando a infra-estrutura universitária disponível. Isto faz sentido se nos reportarmos à predominância, no Estado, das classes tecnológicas conhecidas como "escalaintensiva", coerentemente com sua especialização produtiva.

Os resultados econométricos também sugeriram que transbordamentos de conhecimento tecnológico não são determinantes da atividade tecnológica, quando consideramos todos os municípios de Minas Gerais. Esta conclusão pôde ser alcançada porque os testes de especificação econométrica não apontaram como necessária a inclusão da variável dependente defasada, a qual, quando incluída como regressora e significativa estatisticamente, é interpretada na literatura como evidência de transbordamento espacial. Entretanto, é possível que existam transbordamentos no interior do agrupamento espacial do tipo AA, referente à área metropolitana de Belo Horizonte, como sugerido pela análise exploratória de dados espaciais.

Este resultado também pode ser explicado pela estrutura urbana do Estado. A predominância de pequenos municípios prejudica a inovação porque estes, em sua ampla maioria, são caracterizados por estreito mercado consumidor, falta de infra-estrutura urbana básica, baixa taxa de escolaridade superior da população adulta, baixo grau de industrialização associada à ausência de diversidade industrial, alto índice de concentração econômica empresarial, além de ausência de empresas dinâmicas ou de infra-estrutura científica. Em síntese, eles não possuem economias de urbanização na escala requerida para gerar inovações, seja porque os indivíduos empreendedores e criativos precisam de ambientes densos em que haja fertilização cruzada ou porque as empresas inovadoras também possuem requisitos locacionais que as conduzem para sítios mais favoráveis. Desta forma, as pequenas cidades, especialmente as mineiras, dificilmente conseguirão se equiparar às metrópoles e às cidades de médio porte nacionais, que possuem excelente infra-estrutura urbana, em termos de atratividade para inovação. Estas sempre terão maior variedade de serviços e maiores economias de urbanização.

Alterar o quadro regional da atividade tecnológica de Minas Gerais é uma tarefa árdua, porque implica reorganizar a distribuição espacial dos requisitos locacionais da inovação. Isto, por sua vez, demandaria a criação de novas centralidades urbanas, o que seria custoso, ou mesmo inviável. 
Entretanto, as nossas conclusões têm algumas implicações em termos de políticas públicas. Primeiro, seria conveniente que houvesse integração e complementaridade das políticas urbana e tecnológica, as quais poderiam atuar em duas frentes.

Na primeira, as políticas públicas deveriam ter como alvo o incentivo à inovação e à propriedade intelectual nos tecidos industriais já existentes em cada município. Isto poderia ocorrer por meio de isenções tributárias para investimentos em $\mathrm{P} \& \mathrm{D}$ e financiamento de capital de risco para empresas intensivas em tecnologia mais avançadas. Além disto, políticas de suporte a iniciativas locais, que induzam empreendedorismo e que dêem condições de nascimento e desenvolvimento a pequenas e médias empresas (como incubadoras e parques tecnológicos) também poderiam ser parte integrante das políticas públicas.

A segunda está relacionada com as recomendações de políticas urbanas, que tentam evitar o fluxo migratório para regiões metropolitanas por meio de investimentos em infra-estrutura urbana, como transporte, energia, saneamento básico e habitação nas pequenas cidades. Ao melhorar as economias de urbanização das cidades pequenas e médias, novas atividades produtivas poderiam ser atraídas, que aliadas às políticas de incentivo à inovação poderiam amenizar o quadro regional da atividade tecnológica no estado.

Em suma, qualquer tentativa de melhorar a distribuição espacial das atividades tecnológicas em Minas Gerais requer investimentos em economias de urbanização. Além disto, é preciso que os pequenos municípios formem uma rede urbana integrada e complementar à cidade que ocupa posição de destaque na hierarquia urbana de sua mesorregião ou região de planejamento. Apenas com o aumento do número de atividades econômicas nestes municípios pequenos é que as migrações em direção às grandes cidades podem se reduzir. Assim, a partir do aumento da importância produtiva destes municípios, a sua atividade tecnológica poderá aumentar, o que também pode ser induzido e acelerado por meio de políticas públicas.

\section{REFERÊNCIAS BIBLIOGRÁFICAS}

Albuquerque, E. M. Patentes e atividades inovativas: uma avaliação preliminar do caso brasileiro. In: Viotti, E. B., Macedo, M. M. (Orgs.), Indicadores de ciência e tecnologia e de inovação no Brasil. Campinas: Editora da UNICAMP, 2003.

. Sistema estadual de inovação em Minas Gerais: um balanço introdutório e uma discussão do papel (real e potencial) da FAPEMIG para a sua construção. Belo Horizonte: CEDEPLAR, set. 2001. (Relatório de Pesquisa).

Albuquerque, E. M.; Simões, R.; Baessa, A.; Campolina, B.; Silva, L. A distribuição espacial da produção científica e tecnológica brasileira: uma descrição de estatísticas de produção local de patentes e artigos científicos. Revista Brasileira de Inovação, Rio de Janeiro, v. 1, n. 2, p. 225-251, 2002.

Anselin, L. SpaceStat tutorial: a workbook for using SpaceStat in the analysis of spatial data. UrbanaChampaign: University of Illinois, 1992.

. SpaceStat version 1.80: user's guide. Urbana-Champaign: University of Illinois, 1995.

Spatial econometrics. Dallas: School of Social Science, University of Texas, 1999.

The Moran scatterplot as an ESDA tool to assess local instability in spatial associaton. In:

Fischer, M.; Scholten, H. J.; Unwin, D. (Eds.), Spatial analytical perspectives on GIS. Londres: Taylor \& Francis, 1996. 
Anselin, L.; Bera, A. Spatial dependence in linear regression models with an introduction to spatial econometrics. In: Ullah, A.; Giles, D. E. A. (Eds.), Handbook of applied economic statistics. Nova York: Marcel Dekker, 1998, p. 237-289.

Arrow, K. J. The economic implications of learning by doing. Review of Economic Studies, 29, p. 155-73, jun. 1962.

Audretsch, D. B.; Feldman, M. P. R\&D spillovers and the geography of innovation and production. American Economic Review, v. 86, n. 3, p. 630-640, 1996.

Benko, Georges. Economia, espaço e globalização: na aurora do século XXI. $2^{a}$ ed. São Paulo: Hucitec, 1999.

Carlino, G.; Chatterjee, S.; Hunt, R. Knowledge spillovers and the new economy of cities. Philadelphia: Federal Reserve Bank of Philadelphia, set. 2001. (Working Paper ; 01-14).

Diniz, C. C. A nova configuração urbano-industrial no Brasil. In: ENCONTRO NACIONAL DE ECONOMIA, 27, Belém. Anais... Belém: ANPEC, 1999.

Desenvolvimento poligonal no Brasil: nem desconcentração nem contínua polarização, Nova Economia, Belo Horizonte, v. 3, n. 1, 1993.

Diniz, C. C.; Gonçalves, E. Possibilidades e tendências locacionais da indústria do conhecimento no Brasil. In: ENCONTRO NACIONAL DE ECONOMIA, 28, Campinas. Anais... Campinas: ANPEC, dez., 2000.

Feldman, M. P.; Audretsch, D. B. Innovation in cities: science-based diversity, specialization and localized competition. European Economic Review, v. 43, p. 409-429, 1999.

Fischer, M. M.; Varga, A. Spatial knowledge spillovers and university research: evidence from Austria. The Annals of Regional Science, v. 37, p. 303-322, 2003.

Florax, R. J. G. M.; Folmer, H.; Rey, S. J. Specification searches in spatial econometrics: the relevance of Hendry's methodology. Regional Science and Urban Economics, v. 33, n. 5, p. 557-579, 2003.

Fransman, M. Conceptualising technical change in the Third World in the 1980s: an interpretive survey. Journal of Development Studies, v. 21, n. 4, p. 572-652, jul. 1985.

Glaeser, E. L.; Kallal, H. D.; Scheinkman, J. A.; Shleifer, A. Growth in cities. Journal of Political Economy, v. 100, n. 6, 1992.

IBGE. Base de informações municipais. $3^{\mathrm{a}}$ ed. Rio de Janeiro: IBGE, 2002a [CD-ROM].

Pesquisa industrial - inovação tecnológica 2000. Rio de Janeiro: IBGE, 2002b.

IPEA. Dados sobre educação - 2000. Disponível em: < http://www.ipeadata.gov.br/ipeaweb.dll/ipeadata?152307203 >. Acesso em: 10 dez. 2004b.

. Dados sobre renda. Disponível em: http://www.ipeadata.gov.br/ipeaweb.dll/ipeadata?1523072 03>Acesso em: 10 dez. 2004a.

Jacobs, J. The economy of cities. Nova York: Random House, 1969.

Jaffe, A. B. Real effects of academic research. American Economic Review, v. 79, n. 5, p. 957-970, dez. 1989.

Jaffe, A.; Trajtenberg, M.; Henderson, R. Geographic localization of knowledge spillovers as evidenced by patent citations. Quarterly Journal of Economics, v. 108, n. 3, ago. 1993.

Johnson, R. A.; Wichern, D. W. Applied multivariate statistical analysis. $3^{\mathrm{a}}$ ed. Englewood Clifs: PrenticeHall, 1992.

Le Gallo, J.; Ertur, C. Exploratory spatial data analysis of the distribution of regional per capita GDP in Europe, 1980-1995. Papers in Regional Science, v. 82, p. 175-201, 2003.

Lemos, M. B.; Moro, S.; Domingues, E. P.; Ruiz, R. M. A organização territorial da indústria no Brasil. In: Negri, J. A.; Salermo, M. (Eds.), Inovação, padrões tecnológicos e desempenho das firmas industriais brasileiras. Brasília: IPEA, 2005. 
Malecki, E. J. Technology and economic development: the dynamics of local, regional, and national change. $2^{\mathrm{a}}$ ed. New York: Longman, 1997.

Manly, B. F. J. Multivariate statistical methods: a primer. London: Chapman and Hall Ltd., 1986.

Markusen, A.; Hall, P.; Glasmeier, A. High tech America: the what, how, where and why of the sunrise industries. Boston: Allen \& Unwin, 1986.

Marshall, A. Princípios de economia. São Paulo: Abril Cultural, 1982.

Moreno, R.; Paci, R.; Usai, S. Spatial spillovers and innovation activity in European regions. Centro Riserche Economiche Nord Sud, set. 2004. (Working paper ; 03-10).

Negri, J. A.; Salerno, M. S.; Castro, A. B. Estratégias competitivas e padrões tecnológicos das firmas na indústria brasileira. Brasília: IPEA, 2004. (Mimeografado).

Pamukcu, T. Trade liberalization and innovation decisions of firms: lessons from post-1980 Turkey. World Development, n. 8, p. 1443-1458, 2003.

Pereira, J. C. R. Análise de dados qualitativos: estratégias metodológicas para as ciências da saúde, humanas e sociais. São Paulo: EDUSP, 156p. 1999.

RAIS - Relação Anual de Informações Sociais. Brasília: Ministério do Trabalho, 2000. (CD-ROM).

Romer, P. M. Increasing returns and long-run growth. Journal of Political Economy, v. 94, p. 1002-37, out. 1986.

Ruiz, R. As estruturas urbanas do Brasil: uma análise a partir do tamanho das cidades. In: ENCONTRO NACIONAL DE ECONOMIA, 32, Salvador. Anais... João Pessoa: ANPEC, 2004.

Silva, A. B. A evolução recente da economia mineira: uma análise municipal. Conjuntura Econômica, Rio de Janeiro, fev. 1997.

Silva, L. A.; Rapini, M.; Fernandes, R.; Verona, A. P. Estatísticas de patentes e atividades tecnológicas em Minas Gerais. In: SEMINÁRIO SOBRE ECONOMIA MINERIA, 9, Diamantina. Anais... Diamantina: CEDEPLAR, 2000.

Simmie, J. Innovation and agglomeration theory. In: Simmie, J. (Ed.), Innovative cities. New York: Spon Press, 2001, p. 11-52.

Sternberg, R.; Arndt, O. The firm or the region: what determines the innovation behavior of European firms? Economic Geography, v. 77, n. 4, out. 2001.

Varga, A. University research and regional innovation: a spatial econometric analysis of academic technology transfers. Boston/Dordrecht/London: Kluwer Academic Publishers, 1998.

Viotti, E. B. National learning systems: a new approach on technological change in late industrializing economies and evidences from the cases of Brazil and South Korea. Technological Forecasting and Social Change, v. 69, p. 653-680, 2002.

Wood, P. Conclusions: innovative cities in Europe. In: Simmie, J. (Ed.), Innovative cities. New York: Spon Press, 2001, p. 231-247. 